\title{
BODY ART AS BRANDED LABOUR: \\ AT THE INTERSECTION OF EMPLOYEE SELECTION AND \\ RELATIONSHIP MARKETING
}

\author{
Andrew R Timming \\ Reader in Management \\ School of Management \\ University of St Andrews \\ St Andrews KY16 9RJ \\ (art2@st-andrews.ac.uk)
}

6 October 2016

Acknowledgements: I am grateful to the editor and five reviewers for their helpful comments. I also kindly thank the participants for their time. 


\begin{abstract}
Using mixed methods, this paper examines the role of body art as a form of branded labour in customer-facing jobs. It brings together employee selection and relationship marketing into one framework, and uniquely conceptualizes body art as an asset in the labour market, rather than the traditional liability. In Study 1, 192 respondents with management experience participated in an online laboratory experiment in which they were asked to rate photographs of tattooed and non-tattooed job applicants in two hypothetical organizations: a fine dining restaurant and a popular nightclub. In Study 2, 20 in-depth, qualitative interviews were carried out with managers, tattooed frontline employees and potential consumers in two real-world service sector firms. The results show how body art can be strategically used to positively convey the brand of organizations, primarily those targeting a younger, 'edgier' demographic of customer. Keywords: aesthetic labour, body art, branded labour, recruitment and selection, relationship marketing
\end{abstract}




\section{INTRODUCTION}

Previous research has focused on the negative effects of tattoos on one's employment chances (Bekhor et al, 1995; Swanger, 2006; Timming, 2015; Timming et al, 2015), but the idea that body art can improve job prospects has, until now, been largely neglected. Using mixed methods, this paper examines the circumstances under which a visible tattoo is perceived by managers to be an asset, rather than the traditional liability. The study draws heavily from the aesthetic labour (Nickson et al, 2001; Warhurst and Nickson, 2007) and branded labour (Pettinger, 2004) literatures to throw a new light on the unique intersection of employee selection and relationship marketing.

Whereas aesthetic labour, as a sociological field of study, focuses on the primacy of employee appearance on the production side, branded labour examines employee appearance on the consumption side, with an emphasis on consumers' perceptions of front-line employees. Bringing these frameworks together, it is argued that visibly tattooed job applicants can present as attractive candidates in the labour market because they can help to positively convey an organization's image, or brand, particularly in firms that seek to target a younger, 'edgier' demographic of customer. Two research questions drive this research forward: (1) can tattoos ever be an asset for job seekers in the labour market and (2) can tattooed front-line employees contribute positively to the organizational brand? The key contribution of the paper lies at the unique intersection of these two questions, wherein the field of relationship marketing is integrated into employee selection.

This research is both timely and important because of the dramatic increase in the number of tattoos in recent years, especially in the United States. Laumann and Derick's (2006) dermatological study reported that nearly one-quarter of US adults 
had, at the time, at least one tattoo. The Pew Research Center (2010) reported that 38 percent of 18-29 year old Americans have a tattoo, 30 percent of which are described as visible; in contrast, 15 percent of 46-64 year olds report having a tattoo, compared to only six percent of Americans 65 years and older. The most recent study on tattoo prevalence (Polidoro, 2014) indicates that, in 2014, 40 percent of US households reported at least one member with a tattoo; in 1999, the corresponding figure was just 21 percent. These numbers represent a significant block of society, and a demographic tidal wave whose implications for recruitment and selection and marketing cannot be ignored.

This paper makes an original contribution to the extant literatures on at least two fronts. First, it inverts the wider literature on the effects of body art by focusing on reverse prejudice and the economic benefits of visible tattoos. Apart from Timming (2011), who argues, perhaps unsurprisingly, that tattoos are beneficial in the recruitment of tattoo artists, the positive effects of body art in the wider labour market have been largely overlooked. Second, the paper brings together the disparate fields of employee selection and relationship marketing into a unique nexus. Several studies have already examined body art in the isolated context of brand marketing, including Patterson and Schroeder (2010: 262), who have argued that '[s]kin as symbolic representation [is] a powerful marketing tool'. Bjerrisgaard et al (2013) employed semiotic analysis to show how tattoos can be used to convey a 'rebellious, transgressive persona' (235) that serves to increase consumer identification with tattoo subculture branding. On the other hand, Dean $(2010,2011)$ and Arndt and Glassman (2012) researched consumers' perceptions of tattooed employees, concluding that body art contributes to a largely negative service experience. Bengtsson et al (2005) show how corporate brand tattoos (see also Orend and Gagné, 
2009) are doubly despised by both the tattoo subculture and mainstream culture. Doleac and Stein (2013) found that consumers are significantly less likely to purchase products from employees with visible tattoos. But this debate about the role of tattoos in branding has unfolded largely in marketing circles, whereas the present study is truly interdisciplinary in that it directly links branding to employee selection decisionmaking and, by extension, to HRM.

In the next section, a conceptual framework is articulated and relevant studies are reviewed. After that, the methods and results of Studies 1 and 2 are reported and discussed, respectively. The paper concludes with a general discussion of both studies and a review of the implications of the research.

\section{AESTHETIC LABOUR, BRANDING AND EMPLOYEE SELECTION}

Warhurst et al (2000) first defined aesthetic labour as the 'supply of embodied capacities and attributes possessed by workers'. Since this pioneering study, the theory of aesthetic labour has examined how managers can leverage employees' physical appearance and corporeal attributes on the production side to promote a positive consumer experience, primarily in the interactive services industries (Witz et al, 2003; Entwistle and Wissinger, 2006; Warhurst and Nickson, 2007). The theoretical roots of aesthetic labour can be traced back to the dramaturgical microsociology of Goffman (1959) and wider literature on impression management (DuBrin, 2011). The key contribution of the aesthetic labour framework is to impress the idea that an employee with the right 'looks' can be just as important as an employee with the right skills, aptitudes or emotional dispositions (Hochschild, 1983; Bolton and Boyd, 2003). Empirically, there are two key strands of research on aesthetic labour (Timming, 2016): one examines individuals who have the 'right' looks and are successful in the labour market, whilst the other investigates those who 
possess the 'wrong' looks and are, therefore, often excluded from labour market participation on the basis of what Warhurst et al (2009) have called 'lookism'.

Within the first strand are studies that examine configurations of physical appearance that are compatible with the image that the company hopes to project. For example, Tews et al (2009) demonstrate how applicant 'attractiveness' positively influences employability ratings, especially for customer-facing roles. This finding is broadly corroborated by Hosoda et al's (2003) meta-analysis. Gatta (2011) notes how hiring managers in clothing retail make decisions in the 'blink' of an eye based on whether they think a potential salesperson (usually salesgirl) would 'look good' in the clothing they sell. Warhurst and Nickson (2009) point to the power of sexual appeal, especially for younger women in sales work. Taken together, these studies suggest that 'desirable' bodily endowments can be a significant asset in employment.

On the other hand is a growing body of research that shows a darker side to aesthetic labour. These studies frequently draw from wider theories of stigma (Goffman, 1963) and prejudice (Crandall et al, 2002) to explain how physical 'defects' are often incompatible with much service sector work. For example, Levay (2014) argues that obesity is a major source of bias in the workplace, with serious financial costs for overweight employees. Rudolph et al's (2008) meta-analysis confirms the negative effect of obesity on one's job chances. Stevenage and McKay (1999) and Jenkins and Rigg (2004) show how facial disfigurement and physical disabilities, respectively, can also reduce applicants' chances of successfully landing a job. Sometimes the stigma does not have to be intrinsic to the body. For example, Christman and Branson (1990) and King and Ahmad (2010) investigate the negative effects of unfashionable or inappropriate clothing on employment chances. 
Traditionally, body art has been situated in the second, negative, strand of research on aesthetic labour (Timming et al, 2015). That is to say, most employers hold generally prejudicial attitudes towards visibly tattooed job applicants (Timming, 2015) because tattoos are empirically associated with any number of what Deschesnes et al (2006: 389) call 'externalized risk behaviours'. But the present study, in something of an about-face, places tattoos within the first strand in arguing that body art can also be seen as an asset in the labour market, as long as an applicant's tattoos are compatible with the organization's wider brand personality (Aaker, 1997). Indeed, this argument is consistent with anecdotal evidence that there has been, in recent decades, what might be called a 'tattoo renaissance' in which body art has figured more positively in mainstream society and popular culture (Kosut, 2006).

Research on 'branded labour' (Pettinger, 2004), which focuses on consumers' perceptions of front-line employees, has its roots in the field of relationship marketing, especially Bitner's (1992) study on 'servicescapes'. In it, she looks at how atmospherics, physical surroundings and décor can promote consumption. Since then, it has been well established in the field of marketing that the appearance of employees can help to project an organization's brand (Berry, 2000; Zeithaml and Bitner, 2003; King and Grace, 2009; Parmentier et al, 2013). Avery et al (2012) illustrate the psychological principle at work here. They show how employee 'representativeness' can positively influence consumer behaviour. In particular, they argue that, where consumers can more closely identify with employees and build a long-term relationship or bond, then customer satisfaction, and thus the propensity to buy, is higher.

Recent advances in service quality and brand personality can also throw a useful light on the marketing potential of visible body art. What is known today as the 
services marketing literature has its roots in Parasuraman et al's (1985) seminal work on the various dimensions that contribute to long-term and loyalty-based relationships between customers and brands. This early study led to the development of the widely validated SERVQUAL scale (Parasuraman et al, 1991), which highlights 'tangibles' as one of five key dimensions of service quality. Tangibility refers not only to the aesthetics of the facilities in which a firm operates, but also to the appearance of its front-line staff. Visible tattoos, it could be argued, offer a unique contemporary opportunity for innovation in services delivery (Berry et al, 2010) inasmuch as they facilitate a bond between the consumer and the brand (or the employee who embodies the brand). Also relevant to this discussion is Aaker's (1997) pioneering research on brand personality, which investigates the way in which an inanimate brand can take on human characteristics. Thus, firms seeking to project an 'exciting', 'youthful' and 'edgy' image could be expected to align their recruitment and selection strategy to pro-actively attract job applicants with visible tattoos. By the same token, firms seeking to project a more 'traditional' brand personality will likely eschew visibly tattooed job candidates due to the fundamental incompatibility between body art and the brand.

In sum, based on this review of the extant literature, it would seem that the unique marketing and branding strategy of an interactive services organization should, in theory, variably impact on the employability ratings of both job applicants with and without tattoos. Specifically, we present:

H1a: Visibly tattooed job applicants will be rated higher on employability than non-visibly tattooed job applicants in those organizations targeting a younger, 'edgier' demographic of customer; and, correspondingly,

H1b: Visibly tattooed job applicants will be rated lower on employability than non-visibly tattooed job applicants in those organizations targeting an older, more traditional demographic of customer. 
These hypotheses are consistent with the argument that the employability of tattooed job applicants is driven not so much by recruiters' perceptions of tattoos, but rather by recruiters' perceptions of customers' views of tattoos (Timming, 2015).

Furthermore, inasmuch as some previous research has pointed to the fact that body art is a potentially gendered phenomenon, with tattoos on women being viewed more negatively than tattoos on men, we also incorporate gender into this framework. The few studies that exist on the gendered nature of body art suggest that tattooed women should be expected to suffer from more negative stereotypes than tattooed men. For example, Swami and Furnham (2007) found that tattooed women are perceived as less attractive, more promiscuous and heavier drinkers than non-tattooed women. Similarly, Baumann et al (2016) found some evidence that tattooed women employees are rated lower by consumers than are tattooed men in front-line service roles. Thus, we present:

H2: Tattooed women will be rated lower on employability than tattooed men.

\section{RESEARCH METHODS OVERVIEW}

To accurately capture the extent to which tattooed employees can contribute positively to organizational branding, two separate studies were indicated. The first study uses a face perception experiment to quantify the effects of visible tattoos on applicant employability ratings in two hypothetical organizations: a fine dining restaurant, where the tattoo is hypothesized to be a liability in the light of its 'traditional' brand personality, and a popular nightclub, where the tattoo is hypothesized to be an asset in the light of its 'exciting' brand personality (Aaker, 1997). It should be noted that these two job contexts are both in highly aestheticized industries, and that this was by design. Inasmuch as previous research has already been conducted on the effects of body art on consumer preferences in the less 
aestheticized contexts of an automobile repair shop and a hospital (Baumann et al, 2016), it was decided that the aestheticized contexts of the fine dining restaurant and the nightclub would offer a fruitful contrast.

Because of the limitations of using hypothetical employment scenarios in experimental psychology, a second, follow-up study was also undertaken. Study 2 employs a series of in-depth, qualitative interviews $(\mathrm{N}=20)$ across two real-world case study organizations to gather narrative data from managers, visibly tattooed front-line employees and, crucially, a sample of potential consumers. These two case studies, a skateboard shop and a pub, are equally aestheticized and were selected for inclusion in this research based on a convenience sample.

\section{STUDY 1 METHODS}

\section{Stimuli}

Eight photographs (four men and four women, all Caucasians in their 30s with roughly the same facial adiposity) were initially chosen as the baseline group from a publicly available image database (www.3d.sk). Each face was photographed with a neutral expression at a $0^{\circ}$ angle under constant lighting. As is common in face perception research, the photographs were standardized for inter-pupillary distance to promote comparability across the images.

The stimuli were created by manipulating all eight baseline photographs using Photoshop. A single 'star' shaped tattoo was chosen as the tattoo condition; the same 'star' image was used across the eight test faces because using different genres of tattoos would have introduced a serious confound into the experiment. The image was digitally placed on the left-hand side of the neck of the four male and four female test faces. Thus, the experiment involved eight baseline faces without the tattoo and eight stimulus faces with the tattoo; the analysis is based on composites that were created 
for each group. Because the faces across both groups were otherwise equal, we are able to statistically unpack the effect of the stimuli on employability ratings. Figure 1 provides an example of a stimulus and baseline image.

To conceal from the respondents, as best as possible, that this study is 'about' tattoos, another eight diversionary faces were added to the experimental line-up. Four male and four female faces were selected for inclusion as a means by which to prevent the respondents from figuring out the study's intent. Although it is likely the respondents noticed that the tattoo stimulus was added to the baseline faces, the presence of the diversionary faces in the line-ups at least created the possibility that the tattoo images were perhaps the diversion, and that the diversionary faces were the test faces.

\section{Data Collection}

To approximate real-world conditions in the experiment, only respondents with management experience were targeted, although the participants were not asked what type of management role they held, nor the sectors in which they worked. In total, 201 participants completed the survey instrument. The respondents reported an average of 5.74 years of management experience $($ s.d. $=5.40)$. Overall, the sample was 51.2 percent female, with an average age of 34.45 years $($ s.d. $=11.04)$. In relation to racial distribution, 78.6 percent of respondents are white, 9.5 percent black, 5.0 percent East Asian, 3.5 percent South Asian and 3.5 percent mixed race. All of the participants are currently resident in the United States of America.

Following Oppenheimer et al (2009), a unique manipulation check was built into the experiment to ensure that respondents were reading the instructions and survey items properly. This screening process led to the exclusion of a number of cases. Two items in the questionnaire were strategically placed to evaluate whether 
respondents were paying attention: a simple math problem $(7+3)$ and another item that listed out 11 hobbies, but only asked respondents to select the two starting with the letter ' $r$ ' (rugby and reading). Nine cases were deleted as a result of inaccurate responses to these two items. This quality control measure ensures that the remaining responses are very likely valid. The total sample size is thus 192 respondents; there were no missing values.

Participants completed the questionnaire via MTurk, a popular online crowdsourcing platform whose samples have been found to be just as reliable, and even more diverse, than traditional samples (Buhrmester et al, 2011). Each respondent was given a nominal payment of $\$ 0.22$ USD to incentivize timely completion of the questionnaire. All respondents provided informed consent prior to participation in the research. Participants were instructed to assume that they were recruiters seeking to hire for two positions. They were then presented with the line-up of test faces and asked to rate how likely they would be to hire each person on a scale of 1 to 7 , where $1=$ extremely unlikely and $7=$ extremely likely. The eight baseline, eight stimulus and eight diversionary faces were randomly presented to respondents twice in two separate conditions, so respondents viewed a total of 48 faces. The first condition asked respondents how likely they would be to hire each job applicant presented to them as a server in a fine dining restaurant. The second condition asked respondents to rate how likely they would be to hire each job applicant presented to them as a bartender in a popular nightclub.

These two job contexts were selected based on the assumption not only that the target customer demographic of the popular nightclub is likely to consist mainly of a younger, 'edgier' population, but also that the target customer demographic of the fine dining restaurant is likely to consist mainly of an older, 'traditional' clientele. In 
short, the rationale for these two job contexts is grounded in an a priori assumption in respect to the target demographic of customer in each organization, and, as will be illustrated, the validity of this assumption is borne out in the data analysis. Finally, it is worth noting that a random number table was used to randomize the presentation of test faces in each block to prevent the respondents from identifying a pattern and the respondents viewed the stimuli in the same, randomized order.

\section{Analysis}

Prior to data analysis, composite variables were constructed by averaging scores across the four male and four female test faces. These composites were then rescaled to the original 7-point Likert. A repeated measures analysis of variance (ANOVA) was then used to evaluate the study's hypotheses. The statistical analyses decompose employability ratings by job context (fine dining restaurant vs. nightclub), applicant gender (male vs. female) and visible tattoo (present vs. absent). Thus, a 2X2X2 repeated-measures ANOVA is modelled.

\section{STUDY 1: RESULTS}

Table 1 reports the results of the main effects of the repeated-measures ANOVA. It should be noted that these main effects, in themselves, do not speak directly to the study's hypotheses; they are reported here because they set the stage for the interaction effects that look at the impact of body art in the fine dining restaurant and the nightclub. There was a main effect of job context, with respondents rating all faces higher in the nightclub $(\mathrm{M}=4.71, \mathrm{SD}=.92)$ than in the fine dining restaurant $\left(\mathrm{M}=4.02, \mathrm{SD}=.85 ; \mathrm{F}(1,190)=93.39, \mathrm{p}<.001, \eta_{\mathrm{p}}{ }^{2}=.330\right.$, Cohen's $\left.\mathrm{d}=-.779\right)$. There was also a main effect of tattoo, with respondents rating tattooed faces lower $(\mathrm{M}=4.22, \mathrm{SD}=.87)$ than faces without a tattoo $(\mathrm{M}=4.52, \mathrm{SD}=.78 ; \mathrm{F}(1,190)=28.25$, $\mathrm{p}<.001, \eta_{\mathrm{p}}{ }^{2}=.129$, Cohen's $\mathrm{d}=-.363$ ). The main effects analysis found that applicant 
gender was not statistically significant, thus suggesting that the sex of face did not affect the ratings.

To test for interaction effects, simple contrasts were generated, along with estimated marginal means (Bonferroni corrected) and pairwise comparisons. The first significant interaction effect, job context $\mathrm{X}$ tattoo, speaks to hypotheses H1a and H1b. A second significant interaction effect, job context $\mathrm{X}$ applicant gender $\mathrm{X}$ tattoo, speaks to $\mathrm{H} 2$.

A significant two-way interaction was found between job context and tattoo $\left(\mathrm{F}(1,190)=136.80, \mathrm{p}<.001, \eta_{\mathrm{p}}{ }^{2}=.419\right)$. This finding implies that ratings of the tattooed faces vis-à-vis the baseline faces differed significantly between the fine dining restaurant and the nightclub. Table 2 reports the findings of this interaction effect. The results strongly suggest that the presence of a tattoo is a significant liability in the context of the fine dining restaurant $(\mathrm{M}=3.38, \mathrm{SD}=1.41)$ and a significant asset in the context of the nightclub $(\mathrm{M}=5.07, \mathrm{SD}=1.10)$. Figure 2 illustrates graphically the interaction effect between job context and tattoo. In the context of the restaurant, the difference between the average rating for tattooed faces and the average rating for baseline faces was -1.29 ; in the nightclub, the difference between the average rating for tattooed faces and the average rating for baseline faces was .69, respectively. In other words, the presence of a tattoo increases one's chances of employment in the nightclub and decreases one's chances of employment in the fine dining restaurant, as expected. On balance, though, the tattoo appears to be a greater liability in the restaurant than it is an asset in the nightclub.

To explore this interaction effect further, three separate repeated-measures ANOVAs were run. It was found that: (i) tattooed faces in the nightclub were rated significantly higher than tattooed faces in the restaurant $(F(1,191)=164.59, \mathrm{p}<.001$, 
$\eta_{\mathrm{p}}{ }^{2}=.463$, Cohen's $\mathrm{d}=-1.336$ ); (ii) tattooed faces in the restaurant were rated lower than non-tattooed faces in the restaurant $\left(\mathrm{F}(1,191)=129.61, \mathrm{p}<.001, \eta_{\mathrm{p}}{ }^{2}=.404\right.$, Cohen's $\mathrm{d}=-1.115$ ); and (iii) tattooed faces in the nightclub were rated higher than non-tattooed faces in the nightclub $\left(\mathrm{F}(1,191)=60.45, \mathrm{p}<.001, \eta_{\mathrm{p}}{ }^{2}=.240\right.$, Cohen's $\left.\mathrm{d}=.622\right)$.

A significant three-way interaction effect was also found between job context, applicant gender and tattoo $\left(\mathrm{F}(1,190)=15.84, \mathrm{p}<.001, \eta_{\mathrm{p}}{ }^{2}=.077\right)$. This finding suggests that the relationship between job context and tattoo differs when a job applicant presents as male or female. Table 3 reports the results of this interaction effect. In the fine dining restaurant, male tattooed faces $(\mathrm{M}=3.43, \mathrm{SD}=1.44)$ were rated higher than female tattooed faces $(\mathrm{M}=3.32, \mathrm{SD}=1.49)$. In the nightclub, male tattooed faces $(\mathrm{M}=4.99, \mathrm{SD}=1.18)$ were rated lower than female tattooed faces $(\mathrm{M}=5.14, \mathrm{SD}=1.18)$.

To explore this interaction effect further, two separate repeated-measures ANOVAs were run. It was found that: (i) there was no difference between male tattooed faces in the restaurant and female tattooed faces in the restaurant $\left(\mathrm{F}(1,191)=3.28, \mathrm{p}=.072, \eta_{\mathrm{p}}{ }^{2}=.017\right.$, Cohen's $\left.\mathrm{d}=.075\right)$ and (ii) female tattooed faces in the nightclub were rated higher than male tattooed faces in the nightclub $\left(\mathrm{F}(1,191)=6.10, \mathrm{p}=.014, \eta_{\mathrm{p}}{ }^{2}=.031\right.$, Cohen's $\left.\mathrm{d}=-.127\right)$. These results provide some evidence, contrary to expectations, that tattooed women can be perceived more positively than tattooed men, at least in the context of the nightclub.

\section{STUDY 1: DISCUSSION}

The results of Study 1 simultaneously confirm the prevailing view that body art can have a negative impact on employment chances (Bekhor et al, 1995; Swanger, 2006; Timming, 2015; Timming et al, 2015), but they clearly show that tattoos can also be an asset for job seekers. Whilst previous research has argued that tattoos in the workplace elicit prejudicial attitudes (Miller et al, 2009), the present study shows that 
visible ink has a mixed effect across different organizations. The results suggest that, depending on job context, the presence of a tattoo can be an asset and a liability, but not in equal parts. In other words, the benefit that the tattooed job candidate enjoys when applying to be a bartender in a popular nightclub is not as great as the disadvantage that he or she faces when applying to be a server in a fine dining restaurant. The results also suggest that applicant gender is an important factor, but only in the context of the nightclub where tattooed women were rated higher on employability than tattooed men.

The research implications for the fields of aesthetic and branded labour are significant. Study 1 points to the fact that the same physical characteristic can be perceived negatively in one context, but positively in another. Thus, 'lookism' (Warhurst et al, 2009), to the extent that tattooed job applicants suffer from it, is ultimately a context-dependent phenomenon. The human body appears to be an effective means through which to convey the 'branded' nature of labour (Pettinger, 2004). This key finding corroborates studies in marketing that accentuate the branding potential of employee appearance (Berry, 2000; Zeithaml and Bitner, 2003; King and Grace, 2009). But Study 1 clearly goes beyond this body of research by linking the wider concept of organizational branding to employee selection decision-making. Specifically, it would seem that hiring managers are inclined to recruit employees whose physical appearance reflects the unique 'brand personality' (Aaker, 1997) of the organization.

Although Study 1 can likely stand on its own as a well-designed and executed face perception experiment, it is limited on at least three fronts. First, it highlights key differences, but does not explain why those differences exist. For example, we know that applicant gender creates a significant interaction effect, but the model cannot tell 
us why this is the case. Second, the tattoo stimulus is singular and standardized, meaning that there is no way in Study 1 to evaluate the impact of different types of tattoos. This is a serious limitation since some genres of body art are expected to be more palatable than others (Timming, 2015). Lastly, the study only probes managers' views, which obviously may (or may not) be correct when it comes to the imputation of customers' perceptions of aesthetic labour and organizational branding. Study 2 tackles these limitations.

\section{STUDY 2 METHODS}

Qualitative, case study research was used in Study 2 to supplement and expand upon the findings reported above. Table 4 reports the composition of the sample of respondents. Two real-world case study organizations were selected, within which were interviewed: (i) the manager in charge of recruitment and selection, (ii) a visibly tattooed front-line employee and (iii) eight potential customers. Thus, in total, 20 respondents were interviewed for Study 2. Of the 20 respondents (including the two hiring managers, two employees and 16 potential customers): twelve were male; nineteen were tattooed; six were university students; and the average age was 28.80 years. The rationale for the fact that the lion's share of potential customers is tattooed is that the focus of this paper is on the supposed link between tattooed employees and tattooed customers; previous research has already examined the negative perceptions that a largely non-tattooed public hold against visibly tattooed employees (Timming, 2015).

As is common in many qualitative studies, 'snowball' sampling was used to compose a non-random, convenience sample. Organizations were selected into the sample provided that their main demographic of customer included primarily sub-35 year olds. Two organizations were approached: a locally owned skateboard shop and 
a popular pub owned by a national chain. These were identified based on the fact that their customer base included a largely youthful and 'edgy' consumer block; indeed, this target demographic was confirmed during the fieldwork. Within each case study organization, interviews were first sought with the manager in charge of recruitment. He or she, in turn, was asked to refer the researcher on to a visibly tattooed employee. Figure 3 displays the visible tattoos of the two customer-facing employees who were interviewed in the study.

In the final stage of the research, eight potential customers fitting the general target demographic of each organization were interviewed and shown the photographs in Figure 3. These 16 respondents were equally targeted via a 'snowball' procedure. They were all young adults living in or around the city in which the case study organizations operated and were identified through the researcher's network. During the interviews, they were asked to reflect on their perceptions of the two case study organizations as well as other organizations in which they had recently encountered visibly tattooed employees.

All 20 of the interviews were conducted face-to-face from January 2015 to October 2015 in a medium sized city in the United Kingdom. The interviews were conducted by the researcher, lasted just over an average of 30 minutes and were digitally recorded and transcribed. Maxwell and Miller's (2008) categorizing strategy was used to analyse the qualitative data. Specifically, the transcripts were initially reviewed to identify a set of key themes that are described in the following section. Once identified, these key themes were solidified through meticulous, line-by-line analysis of the data and then organized into matrices prior to the writing up of the results.

\section{STUDY 2: RESULTS}




\section{The Case Study Organizations}

As noted, two case study organizations were examined. The first, SkateCo, is a skateboard and apparel shop. Jackson, the manager, describes the organizational culture at SkateCo as 'street style' and 'hip hop'. The company uses what he calls 'guerrilla marketing' (see also Ay et al, 2010) to appeal to 'the rebellious side, not to be too cliché, but a different side of mainstream'. He encourages 'creativity' in staff appearance, and tattoos reflect 'the artistic lifestyle that we try to propagate'. The second case study is PubCo, a nationwide chain of pubs. Meghan, the regional operations manager, shared a similarly pro-tattoo philosophy, noting, 'we encourage individuality and creativity for every single individual who works for us'. She repeatedly described PubCo's image as ‘edgy' and articulated a unique managerial strategy that might aptly be called 'performance-related tattoos':

Some of our staff incentives are things like paying for a custom designed tattoo ... You know, we're a little bit out there on the edge of perhaps what some employers would feel is acceptable, but we do incentivize our staff with things that they're interested in ... If it's something that someone's really passionate about ... we'll incentivize them with it. You hit targets A, B and C this year and we'll give you $\mathrm{X}$ amount towards your next tattoo project.

Both Jackson and Meghan admitted to encouraging employee self-expression in the form of body art, but were quick to note that certain genres of tattoos would be unacceptable in their places of business. Jackson drew the boundary at anything depicting 'hate speech' and Meghan rejected 'offensive' material, including images that are 'racially abusive' or that project 'inappropriate language'.

Two customer-facing employees, one at SkateCo and another at PubCo, were also interviewed (see their tattoos displayed in Figure 3). Referring to SkateCo, Justin explained, 'we have the kind of culture that's associated with tattoos ... we've got a skate vibe ... At the end of the day, it's a lifestyle for us ... It's just, basically, be 
yourself, you know?'. He went on to describe how his visible tattoos form a basis for 'bonding' with a customer base that is also largely tattooed: 'All these people have got tattoos, so they obviously like looking at tattoos everyday, and then they're coming in here and looking at us with tattoos, because that's who they want to be'. In similar vein, Josh, who works at PubCo, describes the organizational culture as 'the same ethics as a punk-rocker, what they're about. They're sort of anti-establishment, anti-corporate, about rising up against what they don't believe in'. Accordingly, tattoos 'fit in with this place. They fit in with my uniform. They fit in with what the bar's about ... They're a bit edgy, I suppose'. Like Justin, he also noted how his body art reflects the customer base and can serve as an important 'conversation-starter'.

\section{Consumer Attitudes Toward Visible Tattoos}

In the light of the fact that all relationship marketing is consumer-driven, only data from potential customers can effectively corroborate the argument that body art can be used to positively convey an organization's image, or brand. On this note, the 16 consumer respondents were shown photographs of the case study employees' tattoos, depicted in Figure 3. Reflecting on Justin's tattoos, Levi drew an interesting link between body art and knowledge and skills:

He probably knows what he's talking about when it comes to skateboards. [Why?] Because a lot of people in the industry are tattooed, meaning a lot of the pro-skaters have a lot of tattoos ... It's also a lot like the art on the back of the boards ... If the community behind your job involves a lot of body art, it's just one more thing to draw you closer to the customers. Your customers are also going to have some body art.

Richard concurred. When asked what he thought about Justin's tattoos, he responded,

'Cool. I like him ... He seems like the kind of person who would know more about the kind of [skateboarding] culture ... He seems like the kind of person who knows his industry'. Before he was even shown Justin's tattoos, Jason recalled frequently 
shopping at SkateCo, noting that tattoos contribute to the organization's 'image' as a 'rock band'. Similar positive comments were made about Josh's tattoos in that they aligned with PubCo's 'edgy' culture, although one respondent expressed unease with the 'Arabic writing' in red along his arm, which could be 'associated with terrorism' (Glendoris). But, generally speaking, it would be fair to conclude that the employees' tattoos were widely perceived to be 'in sync' (Niki) with the alternative sub-cultures associated with SkateCo and PubCo: 'I guess they're not particularly mainstream, and neither are tattoos' (Stephen).

Asked to reflect more widely on why tattoos can take on positive meaning in certain job contexts, the respondents pointed to the influence of the media and the target demographic of the company. For example, Frankie notes:

I think there are a variety of industries where having a visible tattoo is probably a positive thing. If you're looking at the fashion industry, for me anyway, in particular, when we look at, maybe, our fashion magazines or things like that, or the brandings that happen, a lot of the people that they're using to sell their merchandise have visible tattoos. So having somebody in the shop that can ape that isn't a bad idea ... I guess in my head there's a counter-culture aspect of tattoos that does appeal to a younger demographic.

This quotation nicely captures the marketing potential of body art insofar as it seeks to build a relationship, or bond, with tattooed consumers. Thus, tattoos, especially in pop culture industries such as fashion retail, are an effective marketing and branding tool, thus reinforcing the contradiction that they can, at the same time, reduce and improve employability. On this point, Carl's observations were highly instructive. Not only is Carl heavily tattooed with full 'sleeves', but he also works as a marketing consultant. He gets his hair cut at a barbershop that is very much aligned with tattoo culture, and for him, tattoos:

... are a big part of the reason I go there, the cultural aspect of that. The environment they've created is very much in line with what I believe. I feel comfortable there. These guys are similar to me. They like nice 
things ... They've put a lot of thought and time into this, into making it the right environment ... Obviously, they're quite stylish, trendy I guess. They've got tattoos ... It just feels right for me to be there. It's like I fit in.

Amelia's comments were equally edifying. She has extensive neck and face tattoos. When asked how they fit in with her job as a receptionist of a tattoo shop, she stated, 'they work very well. Because I have so many tattoos, people will always stop me in the street and ask, "Where did you get your tattoos done?". So I'm basically a good advert, well, if people like the tattoos, I'm a very good advert for the shop'.

Although the 16 consumer respondents were brought into the study to throw light on how body art links to organizations' relationship marketing strategy, some also provided interesting insights into the link between body art and employee selection decision-making. For example, when asked whether tattoos could have marketing implications for firms, Diana responded:

Yeah, an example of that would be [PubCo]. The bar [PubCo]. A lot of their staff actually have the [PubCo] logo tattooed on them. Because it's like a, "I'm proud to work here" type of thing ... and actually, a friend of mine got the [PubCo] logo tattoo, which I thought was crazy and a bit stupid, but he got it tattooed and then later he went and worked for [PubCo] and they said, "If you didn't have that tattoo, that tattoo made us love you."

Thinking outside the box, Ailsa speculated about why employers may want to target job applicants with visible tattoos in recruitment and selection. She noted that a tattoo:

is indicative of creativity, and being an individual and not being somebody who's afraid to try things. So I think those are positive attributes. It certainly depends on what kind of job you're looking for [but] creativity, being able to make your own decisions, being an individual, I think they're all worthy attributes of someone who you might want working for you.

Quotations such as these give an innovative and fresh perspective in relation to how tattooed job applicants can find success in this unique segment of the labour market. 
But, of course, not all tattoos are created equal. In fact, every tattoo is a unique signifier that communicates something about the personality of its canvas. To this end, much of the discussion with potential consumers centred around the types, or genres, of tattoos that would be considered inappropriate in any workplace. Responses to this question include: 'images that support fascism' (Ailsa), 'someone with a picture of a dick on their arm' (Al), 'a homophobic tattoo' (Diana), 'something satanic' (Levi) or 'misogynistic' (Cherie), 'the Nazi swastika' (Niki), 'some kind of violent tattoos' (Richard), 'nationalist tattoos' (Oliver), 'anything sectarian' (Stephen), tattoos 'depicting sexual violence' (Frankie), and anything related to 'drugs and sex and alcohol' (Linden), although everyone recognized to an extent that 'the offensive thing is quite hard to figure out, because what offends me might not offend you' (Jason). In addition to the genre of the image, it was also noted that the location of the tattoo is equally important: 'A face tattoo is too much' (Richard). Thus, whilst there is ample evidence that body art can improve a job applicant's employability in certain parts of the labour market, the nature of the art and its placement on the body can still have a negative effect, regardless of job context.

Finally, given the mixed findings in Study 1 in relation to applicant gender, the respondents were asked to reflect on the gendered dimensions of body art. It should be noted that none of the respondents, male or female, expressed any negativity toward women with tattoos, however, they were all able to point to negative perceptions held by society at large. It is perhaps not surprising that the female respondents were much more likely than men to think that tattoos are perceived more negatively on women. Alina lamented having the 'ubiquitous tramp stamp', a tattoo on her lower back. Providing a male perspective, Frankie noted:

I think in general people will look at women with a tattoo in a different way than they would look at a man. You know, I don't imagine that 
there is anything like the male equivalent of the tramp stamp, for example. The mere fact that that term exists and has the derogatory sentiment about it ... I don't think that there's a male equivalent on that.

Respondents outlined several stereotypes that surround tattooed women. For example, they suggested that tattooed women are viewed as 'somehow sexually promiscuous' (Oliver), 'slutty' (Stephen), 'lesbian' (Frankie) or generally 'less feminine' (Ailsa). Alina summarized the attitudes shared across the respondents: 'I think a woman with full sleeve tattoos would be judged more harshly than a man in the same kind of environment'.

\section{STUDY 2: DISCUSSION}

The in-depth, qualitative nature of Study 2 adds significant value on at least three levels in relation to the wider question at the heart of this paper on the role of body art as a form of branded labour. First, the interviews with the managers provided supporting evidence and rationale in respect to the findings in Study 1. Specifically, the managerial respondents confirmed that, especially for organizations pro-actively targeting a younger, 'edgier' demographic of customer, visible tattoos are very much integral to the 'servicescape' (Bitner, 1992) and 'tangibility' (Parasuraman et al, 1991) of the brand personality (Aaker, 1997). Second, Study 2 explicitly incorporated the viewpoints of tattooed employees and potential consumers, both of whom were silent and implicit in Study 1. Third, the qualitative data shone light on the underlying 'mechanism' that was, again, only implicit in Study 1. Specifically, the interviewees confirmed that employee 'representativeness' (Avery et al, 2012) of the customer base positively influences consumer perceptions of the organization and promotes bonding between the consumer and the brand.

The findings in relation to the importance of tattoo genre have important implications not only for Study 1, but also arguably for any study in existence arguing 
that there is a relationship between 'tattoos' and a given set of outcomes. Any such argument is dubious on the basis of the fact that every tattoo is, semiotically speaking, a unique signifier, although it is recognised that the significance of tattoos has become increasingly commodified (Larsen et al, 2014). Nevertheless, the meaning of the image depends on the unique context in which it presents itself and on the eye of the beholder. Thus, we cannot (or should not) speak of the effects of 'tattoos', in general. A much more nuanced approach is needed in which the effects of body art are broken down by genre (Timming, 2015; Timming and Perrett, 2016). For example, Study 1, in and of itself, leads to the conclusion that tattoos increase a job applicant's employability ratings in the context of a nightclub, but Study 2 offers an important qualification, i.e., that some tattoos increase employability whilst others decrease employability. The nature of the image is paramount in this calculation.

Lastly, it is worth noting that Study 2 was able to explore the gendered nature of body art in the workplace, but certainly more research is needed on that dimension of the analysis. Studies have shown that women are subject to significant prejudice on the basis of their tattoos (Swami and Furnham, 2007; Baumann et al, 2016), and indeed Study 2 confirms this much. However, the results of Study 1, in contrast, suggested that tattoos are associated with increased employability of tattooed women in the nightclub. This contradiction between Study 1 and Study 2 requires further exploration and clearly points to an extra layer of complexity in the gendered analysis of body art.

\section{GENERAL DISCUSSION AND CONCLUSIONS}

Tattoos have been extensively researched from the point of view of employee selection (Bekhor et al, 1995; Swanger, 2006; Timming, 2015; Timming et al, 2015) and relationship marketing (Bengtsson et al, 2005; Totten et al, 2009; Patterson and 
Schroeder, 2010; Dean, 2010, 2011; Arndt and Glassman, 2012; Doleac and Stein, 2013; Bjerrisgaard et al, 2013), but this study marks the first time that the two fields have been brought together into one analysis. Drawing from the literature on aesthetic and branded labour (Warhurst et al, 2000; Witz et al, 2003; Pettinger, 2004; Entwistle and Wissinger, 2006; Warhurst and Nickson, 2007), this paper argues that visible tattoos on front-line service employees can not only promote relationship building with tattooed customers, but also, under a unique set of circumstances, concomitantly improve visibly tattooed job applicants' employability. The present study follows the ostensibly counter-intuitive logic of previous research that has managed to positively re-frame what is traditionally viewed as a negative stigma (Toyoki and Brown, 2014). It also demonstrates that body art is a gendered phenomenon, although further research is needed to better understand how and why tattoos are perceived differently on men and women.

Stemming from this research are some potentially problematic implications for visibly tattooed job applicants. For example, Study 1 seems to suggest, at first glance, that job seekers with visible ink should deliberately target some organizations whilst avoiding others. Insofar as tattoos are incompatible with the aesthetic 'branding' of an organization, one might be apt to conclude that visibly tattooed applicants would do well to apply elsewhere, especially in the light of the fact that body art is not a legally protected category (Elzweig and Peeples, 2011). However, this paper stops short of making such a recommendation on ethical grounds. Whilst it might make intuitive sense for visibly tattooed job seekers to target their efforts on organizations with an 'exciting' brand personality (Aaker, 1997), like PubCo and SkateCo, the ideal to which we should strive, as a society, is one of inclusiveness and the rejection of stereotypes in the labour market. 
There are equally important practical and policy implications for employers and organizations, chief among them the need for a more pro-active coupling of a firm's recruitment and selection and relationship marketing strategies. Both Study 1 and Study 2 point to the need for a strategic alignment between the two areas. For all practical purposes, this might mean articulating a set of marketing-informed dress and appearance guidelines for use in selection decision-making. It is also important for organizations to guard against unconscious bias in recruitment and selection. This might be relevant, for example, where an older manager who is perhaps personally antagonistic towards body art is hiring for a customer-facing position where body art is an asset from the point of view of the consumer base.

\section{Limitations and Directions for Future Research}

Although the multi-method 'triangulation' approach taken in this research is a real strength that clearly adds to the robustness of the findings, there are also a series of limitations that, whilst arguably not devastating to the integrity of the analysis, deserve mention nonetheless. First, the sample of managerial respondents from Study 1 only provides limited information about their management experience. For example, we do not know from which industries their experience derives and we do not know whether the respondents have tattoos. The exclusion of this information from the analysis was based on the consideration that a $2 \mathrm{X} 2 \mathrm{X} 2$ repeated-measures design is already a very complex model that would become virtually uninterpretable with the addition of those factors. Having said that, further research should seek to explore the impact of industry experience, especially for managers operating in, for example, the creative industries (Townley et al, 2009), as well as possible effects of whether or not a hiring manager has a tattoo. 
Equally, a limitation of Study 2 is that it focuses almost exclusively on the attitudes of potential customers that are tattooed, thus ignoring the possibility that consumers without tattoos are perhaps just as inclined to purchase a good or service from tattooed employees simply because they 'look the part', so to speak. Future research should, therefore, examine the question of whether a shared characteristic, like a tattoo, is really necessary for a consumer to build a long-term and positive relationship with a brand.

It should also be noted that Study 1 was carried out from a sample of managers based in the United States whilst Study 2 was carried out in the United Kingdom. The cross-national nature of the study design could be perceived as a limitation (although no studies exist pointing to fundamental differences in attitudes toward tattoos in the two countries). Having said that, the cross-national nature of the study design could equally be viewed as a strength in the sense that relationships that are confirmed not only across two research methods, but also two countries, point to a potentially very high level of robustness.

Several alternative directions for future research could potentially be explored, particularly in relation to theory development. Whilst the present study is obviously very empirically driven, it raises some interesting theoretical questions that deserve closer attention. For example, the findings seem to suggest that tattoos in the workplace could constitute a form of organizational governmentality (Burchell et al, 1991). By this is meant the idea that organizations often exert coercive, yet subtle, control over employees' appearance, which is clearly evident from the discussion of 'performance-related tattoos'. Future researchers could thus perhaps bring Foucauldian theory to bear on the subject matter, with particular reference to organizational control over employees. Related to this point is the need for a unifying 
theory that explains the impact of wider unconventional appearance on relationship and services marketing. Beyond tattoos, one could also look at, for example, the effect of job applicant obesity (Rudolph et al, 2008; Levay, 2014) and how it can become an asset in the context of employment in a plus-sized clothing store (Gruys, 2012). Finally, given that gender emerged as an important, but as yet unclear, category of analysis across both studies, it would seem to make sense that future research takes a closer look at potential gender differences in relation to the stigma of body art in the workplace.

It is important to note, in closing, that any further research on the effects of tattoos in the workplace should be carried out promptly. Given the swift growth in the prevalence of tattoos in recent decades, it is very likely that, in the not-too-distant future, body art may well lose its counter-cultural brand. As tattoos become more and more taken-for-granted within the wider society (Kosut, 2006), they will very likely become a less effective means by which to differentiate an organizational identity as 'edgy'. 


\section{REFERENCES}

Aaker, JL (1997) Dimensions of Brand Personality. Journal of Marketing Research XXXIV(August): 347-356.

Arndt, AD and Glassman, M (2012) What Tattoos Tell Customers About Salespeople: The Role of Gender Norms. Marketing Management Journal 22(1): 50-65.

Avery, DR; McKay, PF; Tonidandel, S; Volpone, SD and Morris, MA. (2012) Is there method to the madness? Examining how racioethnic matching influences retail store productivity. Personnel Psychology 65(1): 167-199.

Ay, C; Aytekin, P and Nardali, S (2010) Guerrilla Marketing Communication Tools and Ethical Problems in Guerrilla Advertising. American Journal of Economics and Business Administration 2(3): 280-286.

Baumann, C; Timming, AR and Gollan, PJ (2016) Taboo tattoos? A study of the gendered effects of body art on consumers' attitudes toward visibly tattooed front line staff. Journal of Retailing and Consumer Services 29: 31-39.

Bekhor, PS; Bekhor, L and Gandrabur, M (1995) Employer Attitudes Toward Persons with Visible Tattoos. Australasian Journal of Dermatology 36(2): 75-77.

Bengtsson, A; Ostberg, J and Kjeldgaard, D (2005) Prisoners in Paradise: Subcultural Resistance to the Marketization of Tattooing. Consumption, Markets \& Culture 8(3): 261-274.

Berry, LL (2000) Cultivating Service Brand Equity. Journal of the Academy of Marketing Science 28(1): 128-137.

Berry, LL; Bolton, RN; Bridges, CH; Meyer, J; Parasuraman, A and Seiders, K (2010) Opportunities for Innovation in the Delivery of Interactive Retail Services. Journal of Interactive Marketing 24: 155-167.

Bitner, MJ (1992) Servicescapes: The Impact of Physical Surroundings on Customers and Employees. Journal of Marketing 56(2): 57-71.

Bjerrisgaard, SM; Kjeldgaard, D and Bengtsson, A (2013) Consumer-brand assemblages in advertising: an analysis of skin, identity, and tattoos in ads. Consumption, Markets \& Culture 16(3): 223-239.

Bolton, SC and Boyd, C (2003) Trolley Dolly or Skilled Emotions Manager? Moving on from Hochschild's Managed Heart. Work, Employment \& Society 17(2): 289-308.

Buhrmester, M; Kwang, T and Gosling, SD (2011) Amazon's Mechanical Turk: A New Source of Inexpensive, Yet High-Quality, Data? Perspectives on Psychological Science 6(1): 3-5.

Burchell, G; Gordon, C and Miller, P (eds) (1991) The Foucault Effect: Studies in 
Governmentality. Chicago: University of Chicago Press.

Christman, LA and Branson, DH (1990) Influence of Physical Disability and Dress of Female Job Applicants on Interviewers. Clothing \& Textiles Research Journal 8(3): 51-57.

Crandall, CS; Eshleman, A and O'Brien, L (2002) Social norms and the expression and suppression of prejudice: the struggle for internalization. Journal of Personality and Social Psychology 82(3): 359-378.

Dean, DH (2010) Consumer perceptions of visible tattoos on service personnel. Managing Service Quality 20(3): 294-308.

Dean, DH (2011) Young adult perception of visible tattoos on a white-collar service provider. Young Consumers 12(3): 254-264.

Deschesnes, M; Finès, $\mathrm{P}$ and Demers, S (2006) Are tattooing and body piercing indicators of risk-taking behaviours among high school students? Journal of Adolescence 29(3): 379-393.

Doleac, JL and Stein, LCD (2013) The Visible Hand: Race and Online Market Outcomes. The Economic Journal 123(November): F469-F492.

DuBrin, AJ (2011) Impression Management in the Workplace. New York: Routledge.

Elzweig, B and Peeples, DK (2011) Tattoos and piercings: issues of body modification and the workplace. SAM Advanced Management Journal 76(1): 13-23.

Entwistle, J and Wissinger, E (2006) Keeping up appearances: aesthetic labour in the fashion modelling industries of London and New York. Sociological Review 54(4): 774-794.

Gatta, M (2011) In the "Blink" of an eye-American high-end small retail businesses and the public workforce system. In Retail Work (edited by I. Grugulis and O. Bozkurt). Basingstoke: Palgrave MacMillan.

Goffman, E (1959) The Presentation of Self in Everyday Life. New York: Anchor.

Goffman E (1963) Stigma: Notes on the Management of Spoiled Identity. New York: Touchstone.

Gruys, K (2012) Does This Make Me Look Fat? Aesthetic Labor and Fat Talk as Emotional Labor in a Women's Plus-Size Clothing Store. Social Problems 59(4): 481-500.

Hochschild, A (1983) The Managed Heart. Berkeley: University of California Press.

Hosoda, M; Stone-Romero, EF and Coats, G (2003) The Effects of Physical Attractiveness on Job-Related Outcomes: A Meta-Analysis of Experimental 
Studies. Personnel Psychology 56(2): 431-462.

Jenkins, SP and Rigg, JA (2004) Disability and Disadvantage: Selection, Onset, and Duration Effects. Journal of Social Policy 33(3): 479-501.

King, EB and Ahmad, AS (2010) An Experimental Field Study of Interpersonal Discrimination Toward Muslim Job Applicants. Personnel Psychology 63(4): 881-906.

King, C and Grace, D (2009) Employee Based Brand Equity: A Third Perspective. Services Marketing Quarterly 30(2): 122-147.

Kosut, M (2006) An Ironic Fad: The Commodification and Consumption of Tattoos. Journal of Popular Culture 39(6): 1035-1048.

Larsen, G; Patterson, M and Markham, L (2014) A Deviant Art: Tattoo-Related Stigma in an Era of Commodification. Psychology \& Marketing 31(8): 670681.

Laumann, AE and Derick, AJ (2006) Tattoos and body piercings in the United States: A national data set. Journal of the American Academy of Dermatology 55(3): 413-421.

Levay, C (2014) Obesity in organizational context. Human Relations 67(5): 565-585.

Maxwell, JA and Miller, BA (2008) Categorizing and connecting strategies in qualitative data analysis. In Handbook of Emerging Methods (edited by SN Hesse-Biber and P Leavy). New York: Guilford Press, 461-478.

Miller, BK; Nicols, KM and Eure, J (2009) Body art in the workplace: piercing the prejudice? Personnel Review 38(6): 621-640.

Nickson, D; Warhurst, C; Witz, A and Cullen, AM (2001) The importance of being aesthetic: work, employment and service organization. In Customer Service (edited by A. Sturdy, I. Grugulis, and H. Wilmott). Basingstoke: Palgrave.

Oppenheimer, DM; Meyvis, T and Davidenko, N (2009) Instructional manipulation checks: detecting satisficing to increase statistical power. Journal of Experimental Social Psychology 45(4): 867-872.

Orend, A and Gagné, P (2009) Corporate Logo Tattoos and the Commodification of the body. Journal of Contemporary Ethnography 38(4): 493-517.

Parasuraman, A; Zeithaml, VA and Berry, LL (1985) A Conceptual Model of Service Quality and Its Implications for Future Research. Journal of Marketing 49(Fall): 41-50.

Parasuraman, A; Berry, LL and Zeithaml, VA (1991) Refinement and Reassessment of the SERVQUAL Scale. Journal of Retailing 67(4): 420-450. 
Parmentier, MA; Fisher, E and Reuber, AR (2013) Positioning person brands in established organizational fields. Journal of the Academy of Marketing Science 41(3): 373-387.

Patterson, M and Schroeder, J (2010) Borderlines: Skin, tattoos and consumer culture theory. Marketing Theory 10(3): 253-267.

Pettinger, L (2004) Brand Culture and Branded Workers: Service Work and Aesthetic Labour in Fashion Retail. Consumption Markets \& Culture 7(2): 165-184.

Pew Research Center (2010) Millenials: A Portrait of Generation Next [Report accessed 3 January 2013 at www.pewsocialtrends.org/files/2010/10/millenials -confident-connected-open-to-change.pdf].

Polidoro, R (2014) Infographic: America's Love for Tattoos Grows. NBC News/Wall Street Journal Poll. [Article accessed 29 July 2014 at www.nbcnews.com/ nightly-news/infographic-americas-love-tattoos-grows-n95486].

Rudolph, CW; Wells, CL; Weller, MD and Baltes, BB (2008) A meta-analysis of empirical studies of weight-based bias in the workplace. Journal of Vocational Behavior 74(1): 1-10.

Stevenage, SV and McKay, Y (1999) Model applicants: The effect of facial appearance on recruitment decisions. British Journal of Psychology 90(2): 221-234.

Swami, V and Furnham, A (2007) Unattractive, promiscuous and heavy drinkers: Perceptions of women with tattoos. Body Image 4(4): 343-352.

Swanger, N (2006) Visible body modification (VBM): Evidence from human resource managers and recruiters and the effects on employment. International Journal of Hospitality Management 25(1): 154-158.

Tews, MJ; Stafford, K and Zhu, J (2009) Beauty Revisited: The impact of attractiveness, ability, and personality in the assessment of employment suitability. International Journal of Selection and Assessment 17(1): 92-100.

Timming, AR (2011) What Do Tattoo Artists Know About HRM? Recruitment and Selection in the Body Art Sector. Employee Relations: The International Journal 33(5): 570-584.

Timming, AR (2015) Visible tattoos in the service sector: A new challenge to recruitment and selection. Work, Employment \& Society 29(1): 60-78.

Timming, AR; Nickson, D; Re, D and Perrett, D (2015) What Do You Think of My Ink? Assessing the effects of body art on employment chances. Human Resource Management (Early View).

Timming, AR and Perrett, D (2016) Trust and mixed signals: A study of religion, tattoos and cognitive dissonance. Personality and Individual Differences 97: 
234-238.

Timming, AR (2016) Aesthetic Labour. In Encyclopaedia of Human Resource Management (edited by A. Wilkinson and S. Johnstone). Cheltenham: Edward Elgar.

Totten, JW; Lipscomb, TJ and Jones, MA (2009) Attitudes Toward and Stereotypes of Persons with Body Art: Implications for Marketing Management. Academy of Marketing Studies Journal 13(2): 77-96.

Townley, B; Beech, N and McKinlay, A (2009) Managing in the creative industries: Managing the motley crew. Human Relations 62(7): 939-962.

Toyoki, S and Brown, AD (2014) Stigma, identity and power: Managing stigmatized identities through discourse. Human Relations 67(6): 715-737.

Warhurst, C and Nickson, D (2007) Employee experience of aesthetic labour in retail and hospitality. Work, Employment \& Society 21(1): 103-120.

Warhurst, C and Nickson, D (2009) 'Who's Got the Look?' Emotional, Aesthetic and Sexualized Labour in Interactive Services. Gender, Work \& Organization 16(3): 385-404.

Warhurst, C; Nickson, D; Witz A and Cullen, AM (2000) Aesthetic Labour in Interactive Service Work: Some Case Study Evidence from the "New" Glasgow. Service Industries Journal 20(3): 1-18.

Warhurst, C; van den Broek, D; Hall, R and Nickson, D (2009) Lookism: The New Frontier of Employment Discrimination? Journal of Industrial Relations 51(1): 131-136.

Witz, A; Warhurst, C and Nickson, D (2003) The Labour of Aesthetics and the Aesthetics of Organization. Organization 10(1): 33-54.

Zeithaml, V and Bitner, M (2003) Services Marketing: Integrating Customer Focus Across The Firm (3 ${ }^{\text {rd }}$ edition). McGraw-Hill: New York. 
FIGURE 1: Example of a Tattooed Face (left) and Baseline Face (right)
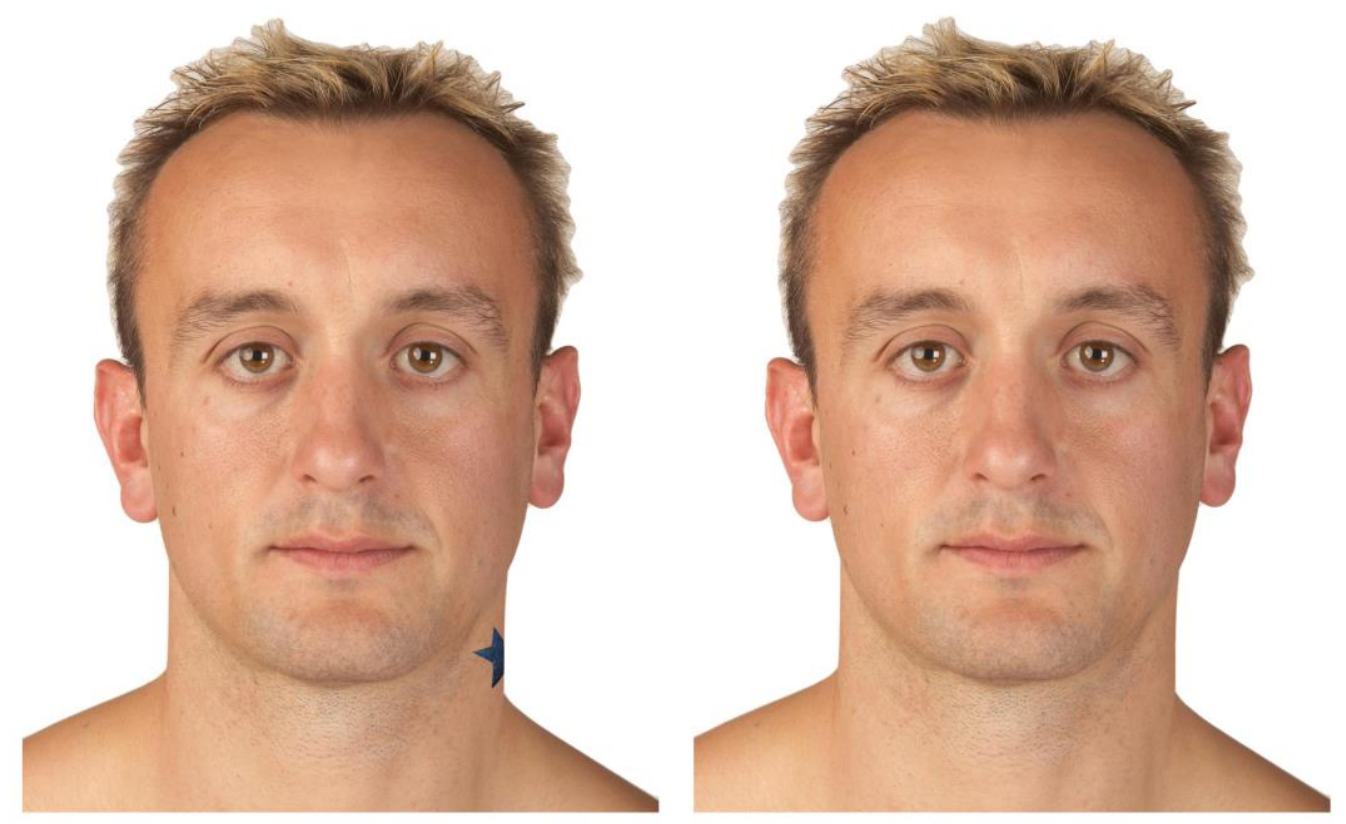
TABLE 1. Main Effects of Employability Ratings in Study 1's 2x2x2 Repeated-Measures ANOVA.

\begin{tabular}{|c|c|c|c|c|c|c|}
\hline & Effect type & Mean rating (SD) & Mean rating difference & $\mathbf{F}$ & $\mathbf{p}$ & $\eta_{p}^{2}$ \\
\hline $\begin{array}{c}\text { Context } \\
\text { (fine dining restaurant; } \\
\text { trendy nightclub) }\end{array}$ & Within-subjects & $\begin{array}{l}\text { Fine dining restaurant: } 4.02(.85) \\
\text { Trendy nightclub: } 4.71(.92)\end{array}$ & -.69 & $\begin{array}{c}93.39 \\
(1,190)\end{array}$ & $<.001$ & .330 \\
\hline $\begin{array}{c}\text { Tattoo } \\
\text { (present; absent) }\end{array}$ & Within-subjects & $\begin{array}{c}\text { Tattoo: } 4.22(.87) \\
\text { No tattoo: } 4.52(.78)\end{array}$ & -.30 & $\begin{array}{c}28.25 \\
(1,190)\end{array}$ & $<.001$ & .129 \\
\hline $\begin{array}{l}\text { Applicant gender } \\
\text { (male; female) }\end{array}$ & Within-subjects & $\begin{array}{c}\text { Male: } 4.39(.78) \\
\text { Female: } 4.36(.80)\end{array}$ & .03 & $\begin{array}{c}.31 \\
(1,190)\end{array}$ & .581 & .002 \\
\hline
\end{tabular}

Cohen's d (restaurant $\mathrm{v}$ nightclub $)=-.779$; Cohen's d (tattoo present $\mathrm{v}$ tattoo absent $)=-.363$; Cohen's d $($ male $\mathrm{v}$ female $)=.038$. 
TABLE 2. Interaction Effect in Study 1 of Employability Ratings between Job Context and Tattoo.

\begin{tabular}{|c|c|c|c|c|c|c|}
\hline \multirow{3}{*}{$\begin{array}{l}\text { Fine dining } \\
\text { restaurant }\end{array}$} & Tattooed faces (SD) & Baseline faces (SD) & Mean difference & $\mathbf{F}$ & $\mathbf{p}$ & $\eta_{p}^{2}$ \\
\hline & $3.38(1.41)$ & $4.67(.83)$ & -1.29 & \multirow{3}{*}{$\begin{array}{l}136.80 \\
(1,190)\end{array}$} & \multirow{3}{*}{$<.001$} & \multirow{3}{*}{.415} \\
\hline & & & & & & \\
\hline Nightclub & $5.07(1.10)$ & $4.38(1.12)$ & .69 & & & \\
\hline
\end{tabular}

Cohen's d (tattooed faces in restaurant $\mathrm{v}$ tattooed faces in nightclub) $=-1.336$; Cohen's d (tattooed faces in restaurant $\mathrm{v}$ non-tattooed faces in restaurant) $=-1.115$; Cohen's d (tattooed faces in nightclub v non-tattooed faces in nightclub) $=.622$. Separate repeated-measures ANOVAs were conducted for each of these pairs and all were statistically significant at the 0.001 level. 
FIGURE 2: Graphical Illustration of Interaction Effect in Study 1 between Job Context and Tattoo.

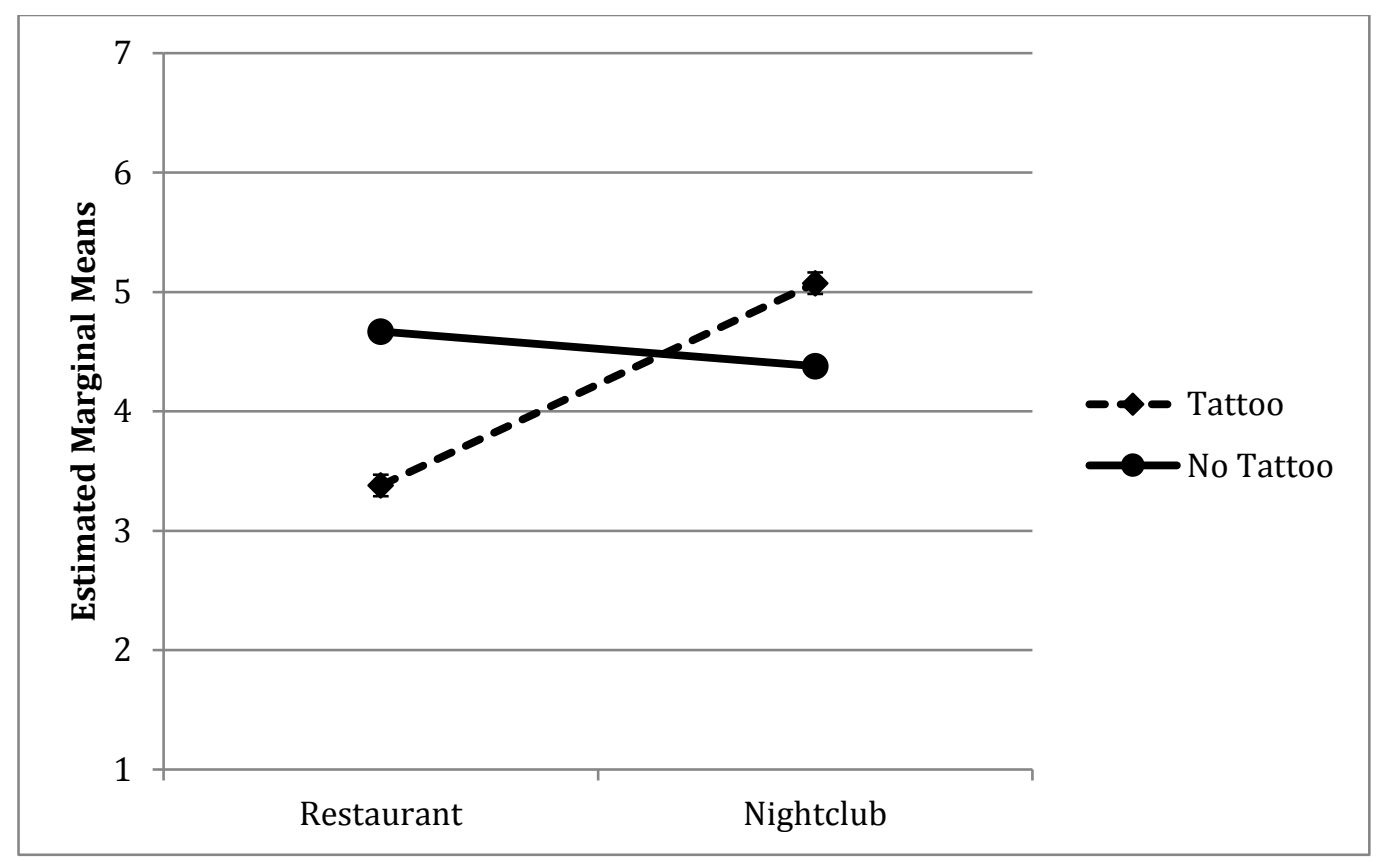


TABLE 3: Interaction Effect in Study 1 of Employability Ratings among Job Context, Applicant Gender and Tattoo.

\begin{tabular}{|c|c|c|c|c|c|}
\hline Tattooed faces (SD) & Baseline faces (SD) & Mean difference & $\mathbf{F}$ & p & $\eta_{p^{2}}^{2}$ \\
\hline
\end{tabular}

\begin{tabular}{|c|c|c|c|c|}
\hline \multirow[t]{2}{*}{$\begin{array}{l}\text { Fine dining } \\
\text { restaurant }\end{array}$} & Male faces & $3.43(1.44)$ & $4.87(.97)$ & -1.44 \\
\hline & Female faces & $3.32(1.49)$ & $4.46(.93)$ & -1 \\
\hline \multirow[t]{2}{*}{ Nightclub } & Male faces & $4.99(1.18)$ & 4.24 (1.27) & .75 \\
\hline & Female faces & $5.14(1.18)$ & $4.51(1.20)$ & .63 \\
\hline
\end{tabular}

Cohen's $\mathrm{d}$ (male tattooed faces in restaurant $\mathrm{v}$ female tattooed faces in restaurant) $=.075$; Cohen's $\mathrm{d}$ (male tattooed faces in nightclub $\mathrm{v}$ female tattooed faces in nightclub) $=-.127$. Separate repeated-measures ANOVAs were conducted for each of these two pairs. The first was not statistically significant at the 0.05 level and the second is significant at the 0.05 level. 
TABLE 4: Composition of Sample and Case Studies for Study 2

\begin{tabular}{|c|c|c|c|}
\hline Case Study & Hiring Manager & Tattooed Employee & Potential Consumers \\
\hline PubCo & $\begin{array}{l}\text { Meghan, } 30 \text {, } \\
\text { female, tattooed }\end{array}$ & $\begin{array}{l}\text { Josh, } 36, \\
\text { male, tattooed }\end{array}$ & $\begin{array}{l}\text { Ailsa, 31, female, employed, tattooed } \\
\text { Carl, 33, male, employed, tattooed } \\
\text { Al, 45, male, employed, tattooed } \\
\text { Alina, 31, female, employed, tattooed } \\
\text { Diana, 30, female, employed, tattooed } \\
\text { Jason, 29, male, employed, tattooed } \\
\text { Amelia, 30, female, employed, tattooed } \\
\text { Glendoris, 37, female, employed, tattooed }\end{array}$ \\
\hline
\end{tabular}


FIGURE 3: Images of Tattooed Employees in Study 2
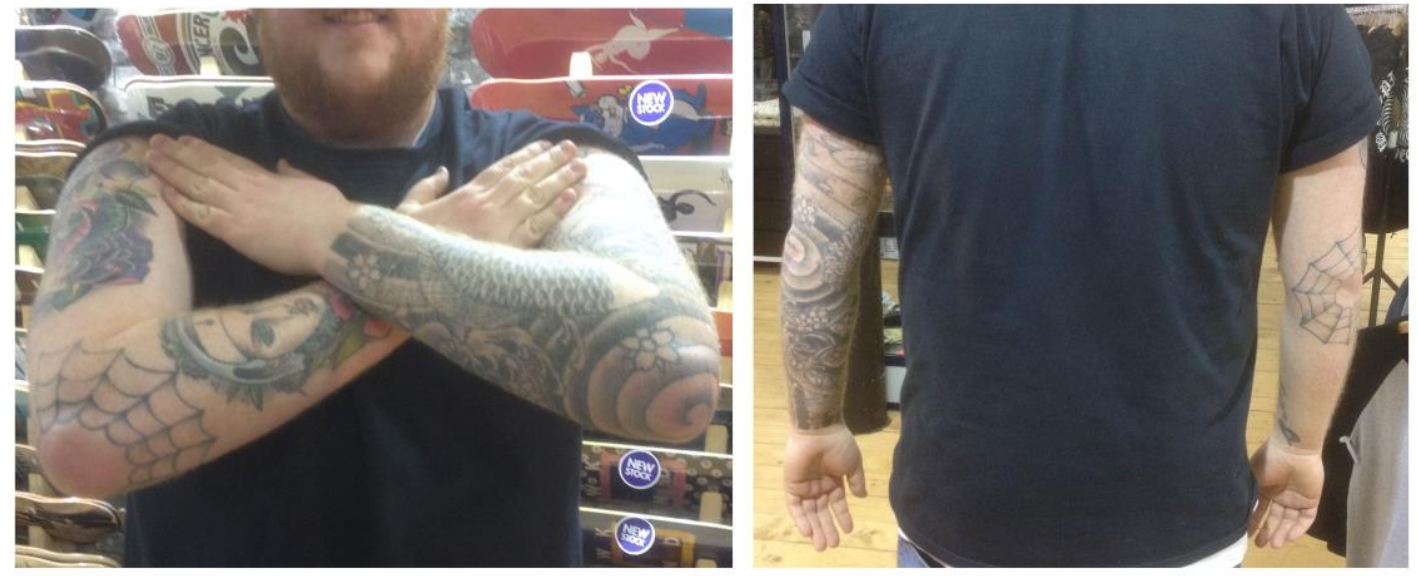

Justin, Skateboard and Apparel Staff
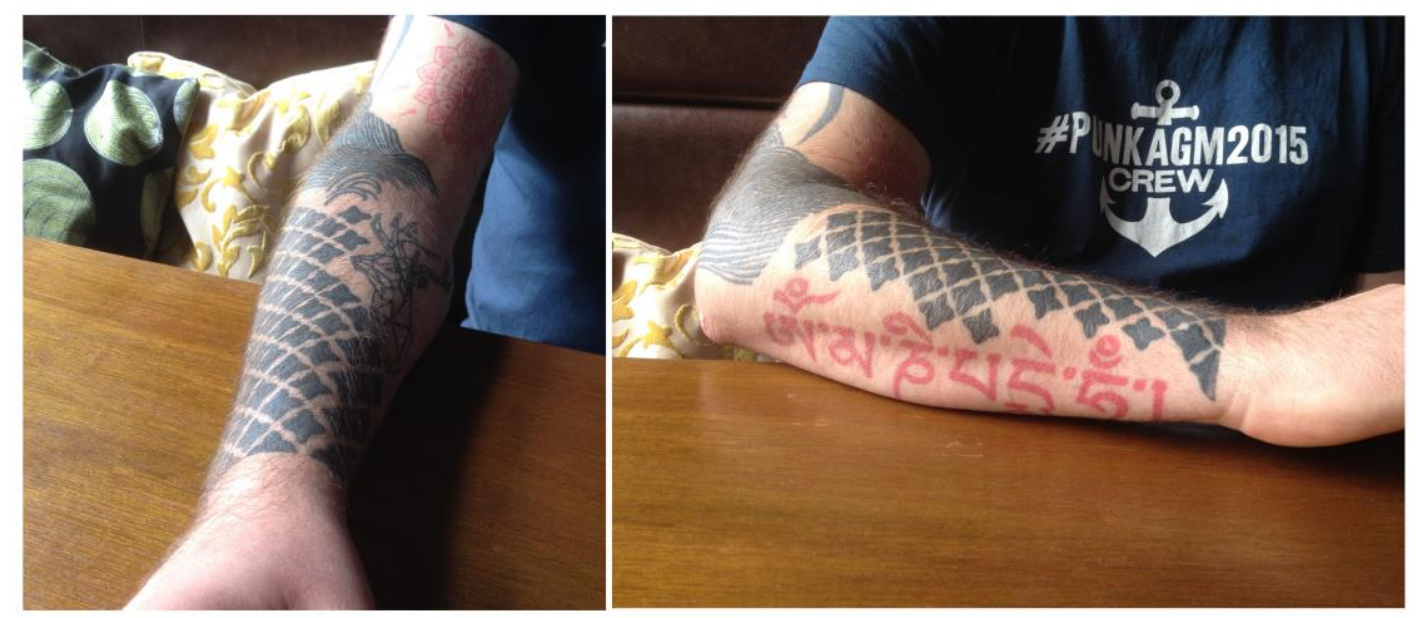

Josh, Bar Staff 